\title{
Trade, Multinational Sales, and FDI in a Three-Factors Model
}

\author{
Peter Egger and Michael Pfaffermayr \\ Austrian Institute of Economic Research \\ Peter.Egger@wifo.ac.at and Michael.Pfaffermayr@wifo.ac.at
}

\begin{abstract}
The overwhelming importance of multinational activities as well as the coexistence of exporters and multinationals within the developed countries demand for theoretical models which provide a convincing explanation of simultaneous two-way trade and horizontal multinational activities. We present a model with three factors of production to disentangle the twofold importance of headquarters for their affiliates into a know-how and a capital serving part (FDI). Multinationals trade-off the incentives for a high proximity to the market and a concentration of production facilities. We simulate the model to derive predictions about the impact of trade costs, plant set-up costs, relative country size and factor endowments on the factor prices of labor, human and physical capital on the one hand and three main output variables, exports, multinational sales and FDI, on the other. We find that the effects are not uniform for multinational sales and FDI. Hence, one should be careful with interpreting the simulation results of previous work for sales as simply holding for FDI as well.
\end{abstract}

JEL classification: F12; F23

Keywords: Multinationals; New trade theory; Endogenous location 


\section{Introduction}

The new trade theory initially has been successful in explaining trade between countries with similar relative factor endowments. Since then not only the pattern of inter-industry and intra-industry trade, but also factor mobility and especially multinational activity came into the limelight of research. One source of this development has been the stylized fact of growing volumes of trade and the increasing importance of foreign ownership of production capital. Although small in levels, in many countries the corresponding growth rates of the latter surpassed those of trade volumes to a large extent. Table 1 demonstrates that (outward) stocks of foreign direct investment (FDI) and volumes of trade as percent of GDP are highest for small developed countries which are relatively well endowed with capital. For instance, the share of intra-OECD trade in World trade amounts to 57 percent $^{1}$. On the other hand, the share of stocks of FDI hosted by OECD countries and owned by other OECD countries in 1995 was about 56 percent of World (outward) FDI ${ }^{2}$. In Table 1 the correlation coefficient between exports and stocks of outward FDI (both measured as percent of GDP) is 0.54 (significant at 10 percent) and that between imports and stocks of inward FDI amounts to 0.36 (again as percent of GDP; significant at 5 percent). Hence, within the OECD trade and FDI are both characterized mainly by a two-way pattern.

$>$ Table 1 about here $<$

It was the merit of Helpman (1984) to incorporate multinational activities into the new standard model of trade for the first time. In contrast to the stylized facts for the OECD countries, Helpman based his explanation of the occurrence of multinational enterprises (MNEs) only on differences in relative factor endowments which would render factor price equalization impossible without MNEs. This type of model has three major limitations. First, the number of multinationals is indeterminate ${ }^{3}$. Second, (as most trade models with MNEs) the MNEs do not serve the foreign country with capital but only with firm-specific assets (headquarters services). This separation of innovation and the production process between two countries implies vertically organized MNEs with the production concentrated in the labor abundant country. Third, counterfactually to the stylized facts for the developed countries, this model only explains one-way MNE activities based on relative factor endowments.

In more recent models the key determinants of multinational activities stem from a trade-off between proximity to the market and concentration of production facilities and are based on the relationship between the costs of setting up a new (second) plant and exporting (barriers to trade, transportation costs). Examples are Brainard (1993), and Markusen \& Venables (1996 and 1998).

\footnotetext{
${ }^{1}$ OECD Monthly Statistics of International Trade (February 2000) and WTO.

${ }^{2}$ OECD International Statistics Yearbook (1997), World Investment Report (1998) with imputations for Japan, Italy and Denmark by the use of outflows.

${ }^{3}$ Helpman considers equilibria with the smallest possible number of multinational firms.
} 
These models are principally able to explain (horizontal) two-way MNE activities combined with two-way trade. However, the considered mixed equilibria with coexisting exporters and MNEs are either indeterminate (Brainard, 1993) or knife-edge cases (Markusen \& Venables, 1998). Markusen \& Venables (1996) is an exception yielding a mixed equilibrium for two-way exports and (homeless) MNEs for a small area in the factor box where country sizes and/or factor endowments are not too similar. Markusen et al. (1996) provide a unified treatment of horizontal and vertical MNEs resulting in a dominance of vertical MNEs for countries with sufficiently different relative factor endowments and of horizontal MNEs for similar countries both in terms of size and relative factor endowments.

We present a model with horizontal MNEs serving their affiliates abroad not only with classical headquarters services (firm-specific assets, knowledge, and production know-how) but also with physical capital. In contrast to both the so-called "vertical" and the "knowledge capital" model, the headquarters in our model are tied to (domestic) plant activities. Our model is built in the tradition of Markusen \& Venables (1996) and accounts for the three main above mentioned stylized facts for the developed countries: First, the dominant role of horizontal $\mathrm{MNEs}^{4}$. Second, the twofold role of headquarters in serving their (foreign) affiliates with both knowledge (innovations) and physical capital, with the latter reflected as a transfer of capital in the balance of payments accounts. Third, the simultaneous existence of exporters and MNEs with both two-way trade and FDI.

We distinguish between physical and human capital which enables us to disentangle headquarters services and the transfer of capital across borders (FDI). As in Markusen \& Venables (1998) we return to the assumption that MNEs establish their headquarters in a particular country and transfer headquarters services and physical capital to the host country.

In contrast to previous work our model demonstrates that the relationship between MNE sales and FDI is not trivial in the sense that a change in the exogenous determinants may exhibit a different impact on the two depending on relative country size and differences in relative factor endowments. This necessiates a more careful interpretation of previous theoretical models which were mainly concerned with MNE sales but sometimes were also interpreted for FDI (see Markusen \& Maskus, 1999a, p. 4).

In order to keep the model as simple as possible, we introduce just one (horizontally) differentiated product. This concentration on intra-industry trade does not allow to analyze trade patterns based on specialization in the production of goods. The empirical evidence indicates, that for developed countries intraindustry trade forms a major part of overall trade (96 percent percent of overall intra-OECD trade in $1995^{5}$ ). Our model, thus, captures the major stylized facts for economic relationships between developed countries as the OECD.

\footnotetext{
${ }^{4}$ Markusen \& Maskus (1999b) show that the horizontal model is also better supported for bilateral U.S. data than the vertical or the "knowledge-capital" models.

${ }^{5}$ Own calculations of the Grubel-Loyd-index for SITC-3-digit trade data (UNO database).
} 
The model uses the now standard ingredients of new models of trade and multinationals: A Heckscher-Ohlin structure determines the pattern of firm types, i.e. exporters (NEs) and MNEs. Both NEs and MNEs face monopolistically competitive product markets. Firms choose between entering the foreign market via exports or FDI on the basis of the proximity-concentration parameters. The former are modelled by fixed costs of setting up a second plant abroad and the latter are iceberg transportation costs. In contrast to antecedent research we provide a three-factors model (labor, physical and human capital) where each of the factors is used in a single process exclusively to keep the model as simple as possible: Human capital serves in the innovation process. Physical capital is the only factor which is needed for setting up a plant (i.e. the production facilities). Labor is used in the production of (differentiated) goods. This rich model structure allows us to explain the widely observed simultaneous occurrence of two-way trade and FDI (cross-hauling) even between absolutely similar countries in terms of both size and relative factor endowments. Empirical evidence on factor endowments supports our view that multinational activities are positively related to both endowments in physical and human capital. More precisely, in the largest possible intersection of the Penn World Table 5.6 and the Barro \& Lee database we find significant positive correlations (at least at 10 percent) between the stocks of outward FDI (as percent of GDP) and both the physical-capital-to-human-capital and the human-capital-to-unskilled-labor ratios in a cross-section of countries in 1995.

The remainder of the paper is organized as follows. Section 2 presents the basic assumptions and the set-up of the model. Since closed solutions of the model cannot be derived, section 3 works out the implications of the general equilibrium in terms of simulations for selected parameter values. Especially, the effects of changes in relative size, relative factor endowments, the transportation cost parameter, and the fixed cost parameter for setting up a foreign plant on the volume of trade, multinational activities, and relative wages are studied. Section 4 summarizes the main results and concludes.

\section{The Model}

\subsection{Demand}

We model demand by a Dixit \& Stiglitz (1977) framework with horizontally differentiated products similar to Markusen \& Venables (1996). In the following, the first subscript $i, j=1,2$ denotes the nationality (country of origin) of the supplier of any variety and the second one refers to the country where the variety is consumed. $x$ is the quantity of a variety if it is exported, $y$ if it is produced by a MNE. In the remainder we use the following convention: if $(i \neq j)$ a variety is either exported or produced by a foreign affiliate. If $(i=j)$ a variety is produced and consumed in the same country. As mentioned above, demand comprises only a single horizontally differentiated product to keep the model tractable. This rules out any considerations about the relations between 
inter-industry and intra-industry trade ${ }^{6}$.

Demand for any variety produced in country $i$ by an exporting firm is given by

$$
x_{i i}=p_{i i}^{-\varepsilon} s_{i}^{\varepsilon-1} E_{i} \quad ; \quad x_{i j}=p_{i i}^{-\varepsilon} t^{1-\varepsilon} s_{j}^{\varepsilon-1} E_{j}
$$

where

$$
s_{i}=\left[\left(n_{i}+m_{i}+m_{j}\right) p_{i i}^{1-\varepsilon}+n_{j}\left(t p_{j j}\right)^{1-\varepsilon}\right]^{1 /(1-\varepsilon)}
$$

is the price aggregator (Markusen \& Venables, 1996). There are $n_{i}$ domestic firms (NEs) exporting to country $j$, and $m_{i}$ MNEs with headquarters in country $i$ and plants in both countries (and similarly for $n_{j}$ and $m_{j}$ ). The underlying assumption is that every firm services both markets either as a MNE or as an exporter (NE). There is no firm which produces only for the home market. So, in contrast to Markusen \& Venables (1996) MNEs produce and sell varieties in both countries. Reimporting a variety from the host country back to the home country is ruled out by costs of transportation. $p_{j j}$ denotes the consumer price for a variety produced and consumed in $j$. Since any variety produced and supplied in the same country (either by MNEs or by NEs) faces the same marginal costs, it has the same price because of the symmetry in market power. This yields identical quantities for all varieties produced and consumed at the same location: $x_{i i}=y_{i i}=y_{j i}$ and $x_{j j}=y_{j j}=y_{i j}$.

If $i \neq j$ and the variety is exported, then NEs have to ship an amount of $t=(1+\tau)$ units to sell one unit of the output in the foreign market, see (1). $\varepsilon>1$ is the elasticity of substitution between the varieties which equals the price elasticity of demand. $E_{i}$ defines the overall factor income (GNP) of country $i$.

\subsection{Factor Requirements}

To capture the main idea of coexisting NEs and MNEs in both countries, the simplest technology uses three factors for three activities (production, plant set-up, and firm set-up) exclusively. Unskilled labor $\left(L_{i}\right)$ is only employed to produce the variety, skilled labor $\left(H_{i}\right)$ is the only factor necessary to invent a blueprint for a new variety (respectively to set-up a new firm). Finally, investment in new plants necessiates only capital $\left(K_{i}\right)$. In contrast to Markusen \& Venables (1996) and other studies, setting up a plant in the foreign country not only demands for the transfer of firm-specific assets ${ }^{7}$, but also a transfer of capital to the host country. We model the latter as shipment of domestic capital to the foreign country and call this FDI although it is not associated with any change in property rights. Hence, capital is treated as mobile in the sense

\footnotetext{
${ }^{6}$ Note that it is nevertheless possible to study the relative importance of intra-industry (inter-firm) and intra-firm trade (in headquarters services).

${ }^{7} \mathrm{~A}$ MNE can use the blueprints in the foreign plant without additional costs. So there are multi-plant economies of scale in the sense of Helpman (1984) and Markusen (1984).
} 
that it can be transferred by a MNE but not via international capital markets. As property rights do not change, this is not associated with a debt position in the capital accounts. In so far, our concept of FDI slightly differs from the accounting convenience in balance of payments statistics. We will refer to this in more detail when discussing the balance of payments constraint.

For simplicity, we rescale the factor supplies to yield unitary input coefficients. Barriers to investment abroad are introduced as a coefficient $(\gamma)$, which makes the investment of one unit of capital abroad more costly than the same investment at home ${ }^{8}$. It may capture legal or other barriers to FDI. Taking into account that $x_{i i}=y_{i i}=y_{j i}$, the factor market clearing conditions for country $i$ (and similarly for country $j$ ) are given by

$$
\begin{aligned}
L_{i} & =\left(n_{i}+m_{i}+m_{j}\right) x_{i i}+n_{i} x_{i j} \\
H_{i} & =n_{i}+m_{i} \\
K_{i} & =n_{i}+(1+\gamma) m_{i}
\end{aligned}
$$

The solutions for the number of varieties provided by exporters $\left(n_{i}\right)$ and multinational firms $\left(m_{i}\right)$ are then easily derived as

$$
m_{i}^{*}=\frac{K_{i}-H_{i}}{\gamma}, \quad n_{i}^{*}=\frac{H_{i}(1+\gamma)-K_{i}}{\gamma}
$$

We only consider cases where the distribution of MNEs and NEs is solely determined by factor endowments and plant set-up costs $(\gamma)$ and both NEs and MNEs of each country are active in equilibrium. Therefore, in the remainder we assume $K_{i} \geq H_{i}$ so that a nonnegative number of headquarters of MNEs exists in each country: $m_{i}^{*} \geq 0,(i=1,2)$. If this condition does not hold, part of a country's human capital endowment would be idle driving its factor reward to zero. The reason for this property lies in the strongly simplified resource constraints. Once $H$ or $K$ would be in use for the production process as well, and, thus, show up in the variable cost terms, this property would disappear. Additionally, $H_{i} \geq K_{i} /(1+\gamma)$ ensures that $n_{i}^{*} \geq 0,(i=1,2)$ and in both countries NEs participate in the innovation process. Moreover and less obviously, we need to restrict the (relative) endowments with unskilled labor in order to guarantee positive factor rewards in both countries and for all factors. Appendix 1 provides a sufficient - however not necessary - condition for that. The gain of this restrictive approach is a clear and simple model structure despite three factors of production in use.

\subsection{Zero Profit Conditions, Entry and Arbitrage}

Factor prices are denoted by $w_{L i}, w_{H i}$, and $w_{K i}$. Marginal costs of production in country $i$ are given by $w_{L i}$ and we normalize - according to Walras' Law -

\footnotetext{
${ }^{8}$ Principally $\gamma<1$ would be associated with an investment subsidy. Although our formulation would allow for this, we do not consider this case in what follows.
} 
$w_{L j}=1$. The fixed plant set-up costs are $w_{K i}$ for the home plant and $\gamma w_{K i}$ for a MNE's plant abroad. Note that capital is transferred to the foreign country $(j)$, but it is likewise rewarded at country $i$ 's rental rate $\left(w_{K i}\right)$ per unit. To generate a blueprint for a new variety, hence, setting up a new firm requires outlays of $w_{H i}$ for one unit of human capital. Summing up, the profits of NEs and MNEs, respectively, are given by

$$
\begin{aligned}
\pi_{i}^{x} & =p_{i i} x_{i i}+p_{i i} x_{i j}-w_{L i} x_{i i}-w_{L i} x_{i j}-w_{H i}-w_{K i} \\
\pi_{i}^{m} & =p_{i i} y_{i i}+p_{j j} y_{i j}-w_{L i} y_{i i}-w_{L j} y_{i j}-w_{H i}-(1+\gamma) w_{K i}
\end{aligned}
$$

Superscripts denote whether a firm is national and exporting $(x)$ or multinational $(m)$ and running 2 plants. Using (1) the first order conditions read

$$
p_{i i}=\frac{w_{L i}}{\theta}, \quad p_{j j}=\frac{w_{L j}}{\theta}
$$

with $\theta$ denoting the mark-up over marginal costs. Under the standard assumptions of monopolistic competition it relates to the elasticity of substitution ( $\varepsilon$ ) via $\varepsilon=\frac{1}{1-\theta}$.

Each firm chooses to enter the foreign market by exports or by setting up a plant abroad looking at the trade-off between variable transportation costs and fixed plant set-up costs. Free entry for both exporters and MNEs in country $i$ yields:

$$
\begin{aligned}
\pi_{i}^{x} & =\frac{w_{L i}(1-\theta)}{\theta}\left[x_{i i}+x_{i j}\right]-w_{H i}-w_{K i}=0 \\
\pi_{i}^{m} & =\frac{w_{L i}(1-\theta)}{\theta} y_{i i}+\frac{w_{L j}(1-\theta)}{\theta} y_{i j}-w_{H i}-(1+\gamma) w_{K i}=0
\end{aligned}
$$

implying

$$
x_{i i}+x_{i j}=\frac{\theta}{1-\theta} \frac{w_{H i}+w_{K i}}{w_{L i}}
$$

for exporting firms and

$$
y_{i i}+\frac{y_{i j}}{w_{L i}}=\frac{\theta}{1-\theta} \frac{w_{H i}+(1+\gamma) w_{K i}}{w_{L i}}
$$

for MNEs. The two zero profit conditions for NEs and MNEs in country $i$ ensure that the difference between the two also is zero $\left(\pi_{i}^{m}-\pi_{i}^{x}=0\right)$ and

$$
y_{i j}-w_{L i} x_{i j}=\frac{\theta}{1-\theta} \gamma w_{K i}
$$


Using the arbitrage conditions for quantities $\left(y_{i j}=x_{j j}\right.$ and $\left.x_{i j}=w_{L i}^{-\varepsilon} t^{1-\varepsilon} x_{j j}\right)$ we arrive at

$$
x_{j j}\left[1-\left(w_{L i} t\right)^{1-\varepsilon}\right]=\frac{\theta}{1-\theta} \gamma w_{K i}
$$

Condition (11) illustrates the difference between our approach and that of Markusen \& Venables (1996) and others to model the trade-off between NEs and horizontal MNEs in a HO-model with monopolistic competition. Assume a situation with two identical countries. This yields factor price equalization although goods transport is costly, and (11) reduces to

$$
x\left[1-t^{1-\varepsilon}\right]=\frac{\theta}{1-\theta} \gamma w_{K}
$$

In this case, the model of Markusen \& Venables (1996) only implies a coexistence of NEs and MNEs for certain parameter combinations of transport costs and fixed costs for plant set-up and innovation. Here, the mixed equilibrium is guaranteed for a large range of parameter values by the possibility of a simultaneous adjustment of the rental rate $\left(w_{K}\right)$ and domestic plant size in both countries $\left(x=x_{i i}=x_{j j}\right)^{9}$.

\subsection{Balance of Payments}

We have to distinguish between exports of goods (final products) and headquarters services which could be interpreted as intra-firm trade. In contrast to Helpman (1984) or Helpman \& Krugman (1985) where MNEs are reimporting the varieties from their foreign affiliates to the home market, in this model intrafirm trade only consists of headquarters services. The latter essentially comprise the innovation of a blueprint, marketing, etc. and can be costlessly supplied to a second plant (multi-plant economies of scale) which generates a public-good nature. Since the headquarters services exhibit a public goods nature within the firm, they have to be allocated implicitly to home and foreign production. We cannot observe the contribution of the innovative activity to an affiliate's profits, so we refer to the associated short-run profits. According to the zero profit conditions these have to cover both the outlays for physical capital and as a residual - also the corresponding contribution to the MNE's human capital costs.

Exports of final products per firm are defined as $p_{i i} x_{i j}$ and $p_{j j} x_{j i}$, respectively. The corresponding country exports in final products are therefore $n_{i} p_{i i} x_{i j}$ and $n_{j} p_{j j} x_{j i}$. The condition for balanced payments, i.e. the current account in our case, reads

\footnotetext{
${ }^{9}$ This holds true as long as factor endowments and parameter values ( $t$ and $\gamma$ ) allow for positive rental rates (see Appendix 1).
} 


$$
n_{i} p_{i i} x_{i j}+(1-\theta) p_{j j} x_{j j} m_{i}=n_{j} p_{j j} x_{j i}+(1-\theta) p_{i i} x_{i i} m_{j} .
$$

Note that in the present model intra-firm trade also is two-way. Because of the possibility of capital movements across borders (FDI), goods trade needs no more be balanced. Trade deficits can be accommodated by income (repatriated profits) from FDI. In contrast to the accounting convenience FDI is a part of a home-country's capital stock which is transported across borders and used in the production process of the host country, which has to pay a fee for this service (i.e. the factor reward of the home country for one unit of capital) but does not buy the capital stock itself. It remains in the home country's property. Hence, borroughing and using production facilities $\left(\gamma m_{i}\right.$ units of physical capital, which is FDI in real units) and sharing know-how ( $m_{i}$ units of human capital) by country $j$ is remunerated by fully repatriating profits from foreign affiliates in $j$ to their home locations in $i$. This shows up in the income component of the current account. The static framework does not consider the corresponding positions in the capital accounts and therefore the balance of payments coincides with the current account in this mode $l^{10}$.

\section{General Equilibrium}

The model consists of 22 unknowns which are the numbers of NEs and MNEs $\left(n_{i}, n_{j}, m_{i}, m_{j}\right)$ and their supplies $\left(x_{i i}, x_{i j}, x_{j j}, x_{j i}\right)$ and $\left(y_{i i}, y_{i j}, y_{j j}, y_{j i}\right)$, 6 factor prices $\left(w_{L i}, w_{L j}, w_{K i}, w_{K j}, w_{H i}, w_{H j}\right)$, and 4 prices of varieties $\left(p_{i i}\right.$, $\left.p_{i j}, p_{j j}, p_{j i}\right)$. Using the 6 factor market clearing conditions, the 4 zero profit conditions, 2 arbitrage conditions for prices for the home and the export market, 6 arbitrage conditions for quantities, 2 remaining first order conditions (FOCs) from profit maximization, and the balance of payments condition we have 21 equations at hand. By Walras' law it is therefore possible to solve this system of equations and to study the properties of the model with respect to interesting parameter constellations. Due to the nonlinearities which are induced by the transportation costs one is not able to solve the problem analytically. Instead, we perform simulations to derive the comparative statics of the system for particular parameter values (see Appendix 2 for more details on the simulation set-up). In order to ensure that all the assumptions are fulfilled in the comparative static exercises, we only will look at small changes in the exogenous variables and parameters.

\subsection{Symmetric Equilibria}

We initially focus on situations with identical countries which are referred to as symmetric equilibria and only consider equilibria with a positive number of

\footnotetext{
${ }^{10}$ In a dynamic model FDI would be treated as investment (implying a change in property rights and a country's debt position) and could show up as a corresponding position to a trade surplus.
} 
NEs and MNEs and positive rewards of all factors in both countries. This on the one hand limits our analysis as - due to our simplifying assumptions about technologies - we cannot analyze equilibria where just one type of firms is active. However, one should note here that other studies work out these cases which were demonstrated to be less suited for the explanation of economic relationships between industrialized countries. On the other hand, this allows to focus our interests on the relationship between national and multinational activities and its dependence on country size, transportation costs, and set-up costs. As in most models, we see that increasing country size (the two identical countries are growing at the same rate) yields both an increasing amount of FDI and exports in either country. This is due to increasing numbers of both NEs and MNEs.

$$
>\text { Table } 2 \text { about here }<
$$

We use the symmetric case mainly to discuss the effects of a reduction in either trade or investment impediments. We have modelled the corresponding barriers in a way that they do not directly affect the country-specific income position. Thus, we should neither think about transport costs as tariffs nor about fixed costs for operating a second plant in a foreign country as a special kind of corporate or other tax rate. Instead, one should interpret both as technical, legal or other kind of barriers which are facing all firms independent of their country of origin. Thus, reductions of these barriers in our model are always symmetrical and, for example, forced by some kind of supranational agreements.

Table 2 summarizes the effects of a c.p. change in costs of transportation or in fixed costs of running a second plant abroad. Similar to other models, higher transport costs $(t)$ favor multinationalization over exporting. The opposite holds true for higher plant set-up costs for foreign affiliates $\left(\gamma w_{K i}\right)$. In all the cases NEs and MNEs do coexist in either country.

An increase in $t$ monotonously lowers the export revenues of the reporting country both in overall as well as in intra-firm exports. The latter result is driven by (i) the arbitrage condition between a firm's exports $\left(x_{i j}\right.$ or $\left.x_{j i}\right)$ and the foreign production of its rival MNE $\left(y_{i j}\right.$ or $\left.y_{j i}\right)$ and (ii) by the zero profit conditions. One yields this outcome as well when measuring exports or intrafirm exports as percent of GNP. On the other hand, both affiliate sales and FDI are positively affected by the increase in $t$.

An increase in $\gamma$ induces the opposite effect on exports, affiliate sales and FDI as an increase in $t$. Intra-firm trade, however, negatively depends on a change in $\gamma$ and positively on a change in $t$. The reason for that lies in the reduction of short-run MNE profits due to higher capital requirements to set-up a foreign plant. In the symmetric case neither a change in $t$ nor one in $\gamma$ exercises an influence on the trade or income balance since factor price equalization is not distorted by (symmetric) changes in $t$ and $\gamma$. According to the simplified technology, only a change in $\gamma$ determines the relationship between the number of MNEs and NEs for given endowments. 


\subsection{Asymmetric Equilibria}

We will consider two different types of asymmetries between countries. First, countries with identical relative factor endowments could differ in size. Second, we look at cases where countries deviate in the endowment of just one factor but are identical in all other respects. The latter refers to the analysis of changes in different relative factor endowments and their effects on the interesting variables. Again, we only consider small changes around the symmetric case.

\subsubsection{Relative Size and the Economy}

To analyze the consequences of a variation in relative size we premultiply country $i$ 's share in world endowments by a factor $v$ which is referred to as the relative size parameter ${ }^{11}$. Since country $i$ 's share was 50 percent in the symmetric case, $v$ tells us, in which direction we are moving from the symmetric case as a starting point. To study the effects of both increasing and decreasing similarity in size we alter $v$ symmetrically around 0.5 .

\section{$>$ Figure 1 about here $<$}

First, we compare the results for the volume of exports from country i's perspective with the standard (new) model of trade. In our, as in the traditional model without transportation costs (Helpman \& Krugman, 1985) country i's exports are an increasing function of similarity in size between the 2 countries. This also holds true for foreign affiliate sales. In neither of the countries the relation between the number of NEs and MNEs is affected by a change in relative size. In Figure 1 country $i$ initially (to the left of $v=0.5$ ) is smaller than country $j$ and its relative size then increases along the abscissa (always holding world endowments constant). This rises its capital and other endowments proportionally and accordingly both the number of MNEs based in country $i$ as well as country $i$ 's capital flows (FDI) in real units to country $j$. If a country gets bigger, it serves the foreign market more and more by MNEs (with smaller and smaller plants) and not so much by exports. However, FDI grows less than proportionally because of the fall in the rental rate in country $i$ relative to $j$. This fall rests on the presence of transport costs which generates a home bias and leads to growing plant sizes in the enlarging country. Foreign affiliate sales are growing faster than exports with country $i$ 's size as long as country $i$ is smaller than country $j$. This difference in shape is due to the wage differential between the two countries. Hence, the relation between country $i$ 's exports and its foreign affiliate sales decreases with its size. The outward orientation of both country i's MNEs and NEs becomes smaller along this line.

MNE sales in terms of GNP for country $i$ are strictly increasing, whereas exports of varieties and invisibles (intra-firm exports) are strictly falling when measured in terms of country i's GNP. As is well-known from other models with transport costs, openness in terms of exports decreases with country size as the

\footnotetext{
${ }^{11}$ One should bear in mind that the relative size parameter $(v)$ measures the size of country $i$ as the share in world GNP. Relative country size is then given by $\frac{v}{1-v}$.
} 
home market bias gets more pronounced. This is also true for FDI in terms of GNP but not for foreign affiliate sales.

Capital is the only mobile factor, for this reason the effect on its relative reward $\left(w_{K i} / w_{K j}\right)$ is more pronounced as compared to relative human capital or labor rewards. Increased shipment of physical capital from $i$ to $j$ via FDI goes hand in hand with a decreasing relative reward on this factor when country $i$ gets larger. This is not the case for the relative rewards to human capital $\left(w_{H i} / w_{H j}\right)$ or labor $\left(w_{L i} / w_{L j}\right)$ which both are positively influenced by domestic market size (in the presence of transportation costs).

\subsubsection{Relative Factor Endowments and the Economy}

To keep things simple we restrict our analysis to three special kinds of changes in relative factor endowments, one for each factor: In any case we leave world endowments unchanged and just alter the endowment in a single factor of one country relative to the other. This seems to be more suited to compare the outcome with the symmetric case as a reference scenario. We introduce a parameter $v$ as an indicator of the difference in the relative endowment with the respective factor ${ }^{12}$. The other two factors are assumed to be equally distributed over both countries. Initially country $i$ is less endowed than country $j(v<0.5)$ in terms of the endowment with one of the factors (labor, human, or physical capital, respectively).

$$
>\text { Table } 3 \text { about here }<
$$

Increasing the relative labor endowment in favor of country $i$ rises the sizes of plants located in that country for both NEs and MNEs, because of sinking relative variable costs of production $\left(w_{L i} / w_{L j}\right)$. The relationship between the numbers of MNEs and NEs is not affected in any of the countries, but the homemarket orientation of NEs is more sensitive than that of MNEs. This follows from the fact that the number of NEs and MNEs is unchanged in any of the countries but the number of NEs exceeds that of MNEs due to our choice of factor endowments in the simulations. Exports of varieties as well as of headquarters services (intra-firm trade) are strictly decreasing functions of relative labor endowments (also in terms of country i's GNP). Hence, the home market growth effect (i.e. the increase in consumption by increasing $L_{i}$ ) more than compensates the decrease in variable costs. With a c.p. increase in $L_{i}$ country $j$ gains a comparative advantage in innovating new varieties which are produced both by its NEs and MNEs. Country i's relative increase in labor endowment implies - since prices are lower there and demand is elastic - that short-run profits of plants in country $i$ increase relative to those in country $j$. Country $i$ now attracts more FDI as exporting becomes relatively less attractive in comparison to going multinational for country $j$ 's firms. Therefore, the relative price of capital $\left(w_{K i} / w_{K j}\right)$ has to decrease. This mechanism guarantees that changes

\footnotetext{
${ }^{12} v$ measures country $i$ 's share of the world endowment of the respective factor. We alter $v$ around the symmetric case $(\nu=\mathbf{0 . 5})$ for each of the three factors.
} 
in relative labor rewards $\left(w_{L i} / w_{L j}\right)$ always move in the same direction as the relative rental rates $\left(w_{K i} / w_{K j}\right)$. Because of a lack in international mobility relative rewards of human capital move in the opposite direction.

To analyze relative changes of $H$ in favor of country $i$ we proceed similarly. Now, the relationship between the number of MNEs and NEs in any of the countries is affected. An increase in $H_{i} / H_{j}$ means that country $i$ gains a comparative advantage in innovating new varieties over country $j$. One yields increasing exports from country $i$ to country $j$ along with decreasing (country $i$ headquartered) MNE sales and intra-firm exports. The increasing comparative advantage in the innovation process along with the increased incentive to serve the foreign market by an affiliate (recall the increased $w_{L i} / w_{L j}$ ratio) also generates relatively more capital outflows (FDI) to country $j$, which is accompanied by dramatic increases in $w_{K i} / w_{K j}$. Note that the associated concavity of the FDI-to-relative-human-capital-endowment locus of country $i$ is due to our assumption of fixed overall world endowments. However, in terms of country $i$ 's GNP both its FDI and exports are increasing, while multinational sales and intra-firm exports are decreasing.

Analysing the effects of increasing relative capital endowments $\left(K_{i} / K_{j}\right)$ we start from a point where country $i$ exhibits a comparative disadvantage in setting up a new (second) plant. Enhancing country $i$ 's capital endowment relative to country $j$ increases $m_{i}$ relative to $n_{i}$. A c.p. change of the distribution of $K$ in favor of country $i$ reduces $n_{i}$ to the same amount as it increases $m_{i}$. Starting from a point where $m_{i}$ is smaller than $n_{i}$ shows that the relationship of $m_{i} / n_{i}$ versus $K_{i} / K_{j}$ is convex. This also results in a pressure on the other factor markets: To employ all the $L_{i}, w_{L i} / w_{L j}$ has to fall. Otherwise too much capital would leave country $i$ and/or too less FDI would flow into the country from outside $(j)$ as $m_{j}$ decreases. In contrast to $L_{i}$, innovations produced with $H_{i}$ are also used by country $i$ 's foreign affiliates without additional costs (the public good characteristics within the firm). The resulting pressure on $w_{L i} / w_{L j}$ conducts higher short-run profits. Since capital in country $i$ becomes more abundant, $w_{K i} / w_{K j}$ is falling. Correspondingly, the zero profit conditions imply a rise in $w_{H i} / w_{H j}$ and a fall in the comparative advantage of country $i$ in setting up a new firm (i. e. innovating new varieties).

In contrast to the symmetric case, unequal relative factor endowments in one of the factors $\left(L_{i} \neq L_{j}\right.$ or $H_{i} \neq H_{j}$ or $\left.K_{i} \neq K_{j}\right)$ imply that a change in $t$ or $\gamma$ affects the trade or income balance as well as the relative factor rewards. Since $t$ influences variable costs of exports of a NE but $\gamma$ changes fixed costs of a MNE only, their impact on wages is not uniform (see Table 4).

An increase in trade costs shifts the trade-off between exports and MNE sales in favor of the latter. Independently of which factor is relatively scarce in country $i$, an increase in $t$ gives a relative disadvantage in exporting compared to going multinational. Although it increases the inward orientation of NEs, the counteracting impact of capital mobility via FDI more than compensates this and lowers $\left(w_{L i} / w_{L j}\right)$.

\footnotetext{
$>$ Table 4 about here $<$
} 
If $L_{i}<L_{j}$ country $i$ holds a comparative advantage in both the innovation process and setting up new plants (i.e. going multinational). An increase in $t$ reduces short-run profits of both NEs and MNEs located in country $i$. Hence, the relative factor rewards of human $\left(w_{H i} / w_{H j}\right)$ and physical capital $\left(w_{K i} / w_{K j}\right)$ will also decrease. The increased foreign affiliate sales are not sufficient to compensate this because of the higher loss in the transportation process. If $L_{i}>L_{j}$, the opposite holds true.

In a situation where $H_{i}<H_{j}$ both $w_{H i} / w_{H j}$ and $w_{K i} / w_{K j}$ increase with $t$. In country $i$ the pressure on wages of labor $\left(w_{L i}\right)$ is higher than in $j$ and as in the example before, because there is a smaller number of NEs active in country $i$. This rises the other two relative factor rewards, as country $i$ 's short-run profits increase.

If $K_{i}<K_{j}$ an increase in trade costs results in similar changes of the relative factor prices as in the case where labor was relatively scarce in country $i$. The effects in a situation with unequal physical capital endowments are generally different from one with unequal human capital endowments. The change in $t$ induces a larger effect on the labor market of that country, which holds a comparative advantage in innovating and producing and therefore more heavily relies on exports (i.e. country $i$ ). This delivers an increase in the short-run profits as mentioned above which is compensated by the countervailing effect of exporting since capital is internationally mobile and human capital exhibits the property of jointness in its use at home and abroad (within firms).

An increase in $\gamma$ generally changes the trade-off between exporting and going multinational in favor of the former (lowering $m_{i} / n_{i}$ ). Remember that a NE in country $i$ produces its output with $L_{i}$ exclusively, which is not the case for a MNE. Therefore, for given wages, the increase in $\gamma$ yields a positive shift in the demand for $L_{i}$ and, in turn, increases $w_{L i} / w_{L j}$ whenever country $i$ is relatively less endowed with a single factor $(v<0.5)$. In real terms, the inward orientation for exporters $\left(x_{i i} / x_{i j}\right)$ rises in contrast to that of the MNEs $\left(x_{i i} / x_{j j}\right)$.

The effects on the other relative factor prices depends on which factor is relatively more scarce in country $i$. If $L_{i}<L_{j}$, the increase in relative wages is accompanied by a rise in both $w_{H i} / w_{H j}$ and $w_{K i} / w_{K j}$ due to the zero profit conditions.

Whenever $H_{i}<H_{j}$, country $i$ conducts less FDI to country $j$, but the capital stock is now used by the NEs which face higher sales as compared to a MNE $\left(m_{i}\right)$. Therefore, the relative reward of physical capital $\left(w_{K i} / w_{K j}\right)$ increases. In contrast, country $i$ then has a comparative advantage in producing a variety and exporting $\left(L_{i} / H_{i}>L_{j} / H_{j}\right)$. Therefore, the outward orientation of a typical country $i$ based exporter gets higher than that of a typical MNE. The international mobility of capital which led to the rise in $w_{K i} / w_{K j}$ together with the public goods nature of $H$ yields a decrease in $w_{H i} / w_{H j}$.

Finally, in a situation where country $i$ is less endowed with physical capital than country $j$ it also has a comparative advantage in exporting vis-à-vis headquartering MNEs. An increase in $\gamma$ again enhances the comparative advantage of country $i$ in exporting. In general, the effects are not different from a situation where country $i$ is less endowed with human capital. 
Summing up, there are 2 clear messages: We interpret a decrease in $t$ as a trade liberalization regime in the sense of lowering non-tariff (e.g. technical) barriers to trade. On the other hand, think about investment liberalization as reducing entry costs for a MNE to a foreign market (as e.g. intended in the Multilateral Agreement on Investment). In our model trade and investment impediments exert opposite effects on the relative rewards (country $i$ / country $j$ ) of all three factors if the two countries only differ in labor endowments. The investment liberalizing regime then reduces relative factor rewards of all factors and the trade liberalization does the opposite in the country which is less endowed with labor. On the other hand, in such a case investment liberalization always reduces relative wages $\left(w_{L i} / w_{L j}\right)$ in that country which is less endowed with one of the respective factors $(L, H$, or $K)$. Again, trade liberalization acts in the opposite direction.

\section{Summary and Conclusions}

The purpose of this paper is to present an endowment-based model of trade and horizontal multinationals which allows for a more convincing analysis of the two with regard to empirical matters of fact. First, the capital serving nature of MNEs beside the headquarters service component is underpinned. This especially should be appropriate as the empirical evidence and the interests of economic policy are mostly based on the mobility of physical capital. We distinguish between the two components of headquarters activities, know-how and physical capital provision. Second, the two way (cross-hauling) character of both exports and FDI simultaneously is a well-known stylized fact at least for relations between the industrialized countries. Albeit taking it into account, former research failed to provide satisfying solutions to this problem within endowment-based static model structures in the presence of a trade-off between proximity to the market and (multi-plant) scale economies.

A model with three factors is able to capture each of the mentioned aspects. The model is simulated to study the effects of a change in costs of transportation or setting up a (second) plant abroad on the relevant variables. Moreover, the three-factors framework proofs to offer more appealing insights into the economic effects of a change in relative factor endowments in the several dimensions.

We find that multinational sales and FDI are affected in different ways, suggesting that the theoretical implications for MNE sales do not necessarily carry over to FDI. For instance, in the present model the former are an increasing function of similarity in size (like exports), whereas outward FDI is increasing with the size of the sending country.

The asymmetry of countries with respect to their size and/or relative factor endowments demonstrates that increasing similarity in different factor dimensions affects relative factor rewards in different ways. They move in the same direction (starting from the symmetric case), if we redistribute either the labor or physical capital endowment but in the opposite for human capital. This prop- 
erty results from the mobility of physical capital and the public goods nature of knowledge within firms.

Trade and investment liberalization in our model imply the opposite impact on relative factor rewards if countries differ in labor endowments only. Interestingly, investment liberalization then leads to a decrease in all factor prices of the country where labor is scarce relative to the other. Trade liberalization does the opposite, since falling trade costs remove the home market bias.

\section{References}

Brainard, Lael S. (1993), A Simple Theory of Multinational Corporations and Trade with a Trade-off between Proximity and Concentration, NBER Working Paper No. 4269.

Dixit, Avinash K. and Joseph E. Stiglitz (1977), Monopolistic Competition and Optimum Product Diversity, American Economic Review 67(3), 297-308.

Helpman, Elhanan (1984), A Simple Theory of International Trade with Multinational Corporations, Journal of Political Economy 92, 451-472.

Helpman, Elhanan and Paul R. Krugman (1985), Market Structure and Foreign Trade, Cambridge, Mass.

Markusen, James R. (1984), Multinationals, Multi-Plant Economies, and the Gains from Trade, Journal of International Economics 16(3-4), 205-224.

Markusen, James R. and Keith E. Maskus (1999a), Multinational Firms: Reconciling Theory and Evidence, NBER Working Paper No. 7163.

Markusen, James R. and Keith E. Maskus (1999b), Discriminating Among Alternative Theories of the Multinational Enterprise, NBER Working Paper No. 7164 .

Markusen, James R. and Anthony J. Venables (1996), The Theory of Endowment, Intra-Industry, and Multinational Trade, NBER Working Paper No. 5529.

Markusen, James R. and Anthony J. Venables (1998), Multinational Firms and the New Trade Theory, Journal of International Economics 46(2), 183-203.

Markusen, James R., Anthony J. Venables, Denise E. Konan and Kevin H. Zhang (1996), A Unified Treatment of Horizontal Direct Investment, Vertical Direct Investment, and the Pattern of Trade in Goods and Services, NBER Working Paper No. 5696. 


\section{A Appendix 1: The Region of Positive Factor Rewards}

Using the zero profit conditions for NEs and MNEs as well as the arbitrage conditions from the demand equations yields

$$
\frac{y_{i j}}{w_{L i}}-x_{i j}=\frac{\theta \gamma w_{K i}}{(1-\theta) w_{L i}} \geq 0 \Longrightarrow y_{i j}=x_{j j} \geq w_{L i} x_{i j}
$$

for $w_{L i}>0$, and similarly

$$
y_{j i}=x_{i i} \geq \frac{x_{j i}}{w_{L i}}
$$

Inserting in (3) gives

$$
L_{i}=\left(n_{i}+m_{i}+m_{j}\right) x_{i i}+n_{i} x_{i j} \leq\left(n_{i}+m_{i}+m_{j}\right) x_{i i}+n_{i} \frac{x_{j j}}{w_{L i}}
$$

$$
L_{j}=\left(n_{j}+m_{j}+m_{j}\right) x_{j j}+n_{j} x_{j i} \leq\left(n_{j}+m_{j}+m_{j}\right) x_{j j}+n_{j} w_{L i} x_{i i}
$$

On the other hand, using (1) and the arbitrage conditions between $x_{i j}$ and $x_{j j}\left(x_{j i}\right.$ and $\left.x_{i i}\right)$ we have

$$
\begin{gathered}
L_{i}=\left(n_{i}+m_{i}+m_{j}\right) x_{i i}+n_{i} x_{i j} \leq\left(n_{i}+m_{i}+m_{j}\right) x_{i i}+n_{i} x_{j j} w_{L i}^{-\varepsilon} t^{1-\varepsilon} \\
L_{j}=\left(n_{j}+m_{j}+m_{j}\right) x_{j j}+n_{j} x_{j i} \leq\left(n_{j}+m_{j}+m_{j}\right) x_{j j}+n_{j} x_{i i} w_{L i}^{\varepsilon} t^{1-\varepsilon}
\end{gathered}
$$

Subtracting (A.1.3) from (A.1.5) and (A.1.4) from (A.1.6) gives

$$
\begin{aligned}
& w_{L i}^{1-\varepsilon} t^{1-\varepsilon} \leq 1 \\
& w_{L i}^{\varepsilon-1} t^{1-\varepsilon} \leq 1
\end{aligned}
$$

So

$$
\frac{1}{t} \leq w_{L i} \leq t
$$


if (A.1.1) holds. (A.1.9), (13) as well as the inequalities above provide a sufficient however not necessary condition ensuring positive rental rates. Thus, positive foreign production for both countries is guaranteed by

$$
\frac{L_{i}\left[\left(n_{j}+m_{i}+m_{j}\right) t^{\varepsilon}-n_{i} t^{1+\epsilon}\right]}{L_{j}\left[\left(n_{i}+m_{i}+m_{j}\right)-n_{j} t^{1-\varepsilon}\right]} \leq \frac{x_{i i}}{x_{j j}} \leq \frac{n_{i} \epsilon+m_{i}}{n_{j} \epsilon t^{1-2 \epsilon}+t^{-1} m_{j}}
$$

We assume that this condition is fulfilled and concentrate on this case.

\section{B Appendix 2: Simulation Results}

We apply the arbitrage conditions for prices and quantities which are mentioned in section 3 and arrive at the following 7 equations in the simulations to obtain numerical solutions for quantities and factor prices

$$
\begin{gathered}
L_{i}-\left(n_{i}+m_{i}+m_{j}\right) x_{i i}-n_{i} x_{j j} w_{L i}^{-\varepsilon} t^{1-\varepsilon}=0 \\
L_{j}-\left(n_{j}+m_{i}+m_{j}\right) x_{j j}-n_{j} x_{i i} w_{L i}^{\varepsilon} t^{1-\varepsilon}=0 \\
x_{i i}+x_{j j} w_{L i}^{-\varepsilon} t^{1-\varepsilon}-(\varepsilon-1) \cdot \frac{w_{H i}+w_{K i}}{w_{L i}}=0 \\
x_{j j}+x_{i i} w_{L i}^{\varepsilon} t^{1-\varepsilon}-(\varepsilon-1) \cdot\left(w_{H j}+w_{K j}\right)=0 \\
x_{i i}+\frac{x_{j j}}{w_{L i}}-(\varepsilon-1) \cdot \frac{w_{H i}+(1+\gamma) w_{K i}}{w_{L i}}=0 \\
x_{j j}\left(n_{i} w_{L i}^{1-\varepsilon} t^{1-\varepsilon}+\frac{m_{i}}{\varepsilon}\right)-x_{i i}\left(n_{j} w_{L i}^{\varepsilon} t^{1-\varepsilon}+w_{L i} \frac{m_{i}}{\varepsilon}\right)=0 \\
x_{j j}+x_{i i} w_{L i}-(\varepsilon-1) \cdot\left(w_{H j}+(1+\gamma) w_{K j}\right)=0
\end{gathered}
$$

From (4) we know that $n_{i}, n_{j}, m_{i}$, and $m_{j}$ are fully determined by factor endowments in human and physical capital. The first two equations, (A.2.1) and (A.2.2), are based on the labor market clearing conditions, while (A.2.3)(A.2.6) follow from the zero profit conditions for both NEs and MNEs, (8) and 
(9). Finally, (A.2.7) represents the balance of payments condition which is given in $(13)$.

All simulations are based on the following values for variables and parameters. $\widetilde{L}=100, \widetilde{H}=100$, and $\widetilde{K}=120$, where the former refers to world endowment of labor, and the latter two are world endowments of human and physical capital, respectively. The elasticity of demand for a single variety is set at $\varepsilon=2$. Values for $t$ and $\gamma$ are reported in the tables. When country size is changed, size of country $i$ varies between 44 percent and 56 percent of world size. According to our assumptions this means that country $i$ holds an equivalent share of the world endowment in any factor. When the impact of different relative factor endowments is analyzed, the endowment of country $i$ in one certain factor varies between 44 percent and 56 percent of world endowment, leaving the countries fully identical in any other respect. 
Table 1: Intra-OECD trade and FDI by country in 1995

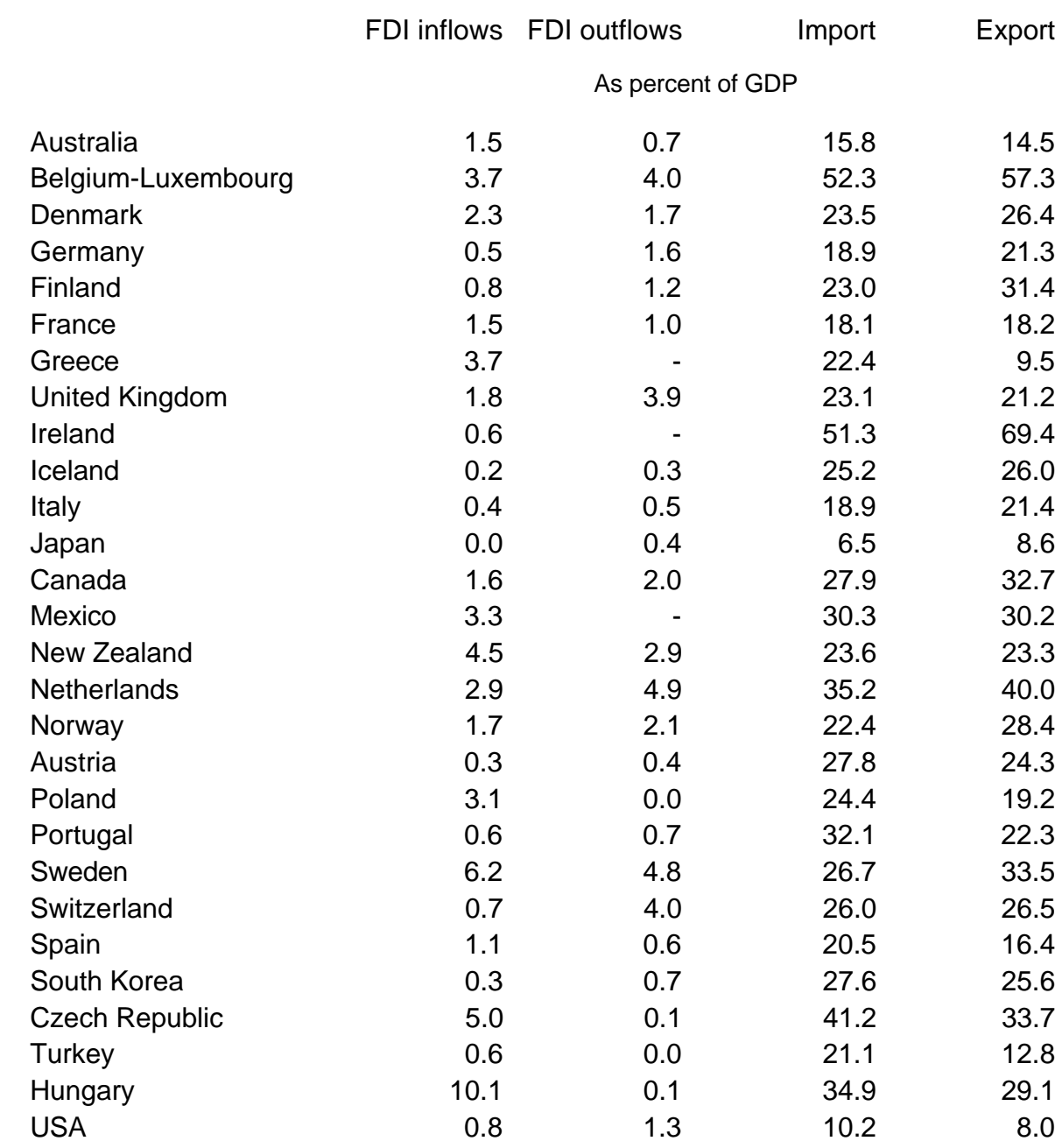

Source: OECD. - = Not available. 
Table 2: Changes in tor $\gamma$ for symmetric countries

Dependent variable in absolute figures

$\begin{array}{cc}\text { Increase in t } & \text { Increase in } \gamma \\ - & + \\ - & - \\ + & - \\ + & - \\ 0 & 0 \\ 0 & 0 \\ 0 & 0 \\ 0 & 0 \\ 0 & 0 \\ 0 & - \\ & \\ - & - \\ - & - \\ + & - \\ + & -\end{array}$

Note: the parametrisation is given in Appendix 2. t varies between 1.01 and 1.25 and $\gamma$ between 1 and 1.24 . 
Table 3: Changes in relative factor endowments (Constant world endowments)

\begin{tabular}{|c|c|c|c|}
\hline & $\mathrm{L}_{\mathrm{i}} / \mathrm{L}_{\mathrm{j}}$ & $\begin{array}{c}\text { Increase in } \\
H_{i} / H_{j}\end{array}$ & $\mathrm{~K}_{\mathrm{i}} / \mathrm{K}_{\mathrm{j}}$ \\
\hline \multicolumn{4}{|l|}{ Dependent variable in absolute figures } \\
\hline Exports $_{i}$ & - & + & - \\
\hline Intra-firm exports & - & - & + \\
\hline $\mathrm{FDI}_{\mathrm{i}}$ & - & + & - \\
\hline Foreign affiliate sales $s_{i}$ & - & - & + \\
\hline Trade balance $_{i}$ & + & + & - \\
\hline Capital balance $_{i}$ & - & - & + \\
\hline $\mathrm{w}_{\mathrm{Li}} / \mathrm{w}_{\mathrm{Lj}}$ & - & + & - \\
\hline $\mathrm{w}_{\mathrm{Hi}} / \mathrm{w}_{\mathrm{Hj}}$ & + & - & + \\
\hline $\mathrm{w}_{\mathrm{Ki}} / \mathrm{w}_{\mathrm{Kj}}$ & - & + & - \\
\hline Number of MNEs in relation to NEs $\left(m_{i} / n_{i}\right)$ & 0 & - & + \\
\hline \multicolumn{4}{|l|}{ Dependent variable as percent of GNP } \\
\hline Exports $_{i}$ & - & + & - \\
\hline Intra-firm exports & - & - & + \\
\hline $\mathrm{FDI}_{\mathrm{i}}$ & - & + & - \\
\hline Foreign affiliate sales $s_{i}$ & - & - & + \\
\hline
\end{tabular}

Note: $\mathrm{t}=1.1$ and $\gamma=1$. The share of country $\mathrm{i}$ in the respective factor endowment $(v)$ varies between 0.44 and 0.56 percent in the world endowment. 
Table 4: The effects of changing tor $\gamma$ on relative wages (Asymmetric relative factor endowments)

\begin{tabular}{|c|c|c|c|}
\hline \multicolumn{4}{|c|}{ 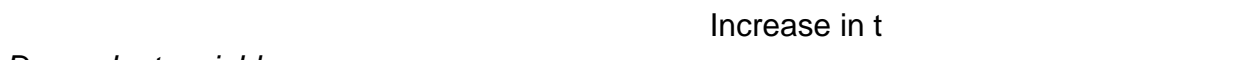 } \\
\hline \multicolumn{4}{|c|}{ Dependent variable } \\
\hline $\mathrm{W}_{\mathrm{Li}} / \mathrm{w}_{\mathrm{Lj}}$ & - (for $\left.L_{i}<L_{j}\right)$ else + & - $\left(\right.$ for $\left.\mathrm{H}_{\mathrm{i}}<\mathrm{H}_{\mathrm{j}}\right)$ else + & - $\left(\right.$ for $\left.\mathrm{K}_{\mathrm{i}}<\mathrm{K}_{\mathrm{j}}\right)$ else + \\
\hline $\mathbf{w}_{\mathrm{Hi}} / \mathbf{w}_{\mathrm{Hj}}$ & - (for $\left.L_{i}<L_{j}\right)$ else + & $+\left(\right.$ for $\left.\mathrm{H}_{\mathrm{i}}<\mathrm{H}_{\mathrm{j}}\right)$ else - & - $\left(\right.$ for $\left.\mathrm{K}_{\mathrm{i}}<\mathrm{K}_{\mathrm{j}}\right)$ else + \\
\hline \multirow[t]{2}{*}{$\mathrm{w}_{\mathrm{Ki}} / \mathrm{w}_{\mathrm{Kj}}$} & - (for $\left.L_{i}<L_{j}\right)$ else + & $+\left(\right.$ for $\left.\mathrm{H}_{\mathrm{i}}<\mathrm{H}_{\mathrm{j}}\right)$ else - & - $\left(\right.$ for $\left.\mathrm{K}_{\mathrm{i}}<\mathrm{K}_{\mathrm{j}}\right)$ else + \\
\hline & & Increase in $\gamma$ & \\
\hline \multicolumn{4}{|c|}{ Dependent variable } \\
\hline $\mathrm{w}_{\mathrm{Li}} / \mathrm{w}_{\mathrm{Lj}}$ & $+\left(\right.$ for $\left.\mathrm{L}_{\mathrm{i}}<\mathrm{L}_{\mathrm{j}}\right)$ else - & $+\left(\right.$ for $\left.\mathrm{H}_{\mathrm{i}}<\mathrm{H}_{\mathrm{j}}\right)$ else - & $+\left(\right.$ for $\left.\mathrm{K}_{\mathrm{i}}<\mathrm{K}_{\mathrm{j}}\right)$ else - \\
\hline $\mathrm{w}_{\mathrm{Hi}} / \mathrm{w}_{\mathrm{Hj}}$ & $+\left(\right.$ for $\left.L_{i}<L_{j}\right)$ else - & - $\left(\right.$ for $\left.\mathrm{H}_{\mathrm{i}}<\mathrm{H}_{\mathrm{j}}\right)$ else + & - (for $\mathrm{K}_{\mathrm{i}}<\mathrm{K}_{\mathrm{j}}$ ) else + \\
\hline$w_{K i} / w_{K j}$ & $+\left(\right.$ for $\left.L_{i}<L_{j}\right)$ else - & $+\left(\right.$ for $\left.\mathrm{H}_{\mathrm{i}}<\mathrm{H}_{\mathrm{j}}\right)$ else - & $+\left(\right.$ for $\left.\mathrm{K}_{\mathrm{i}}<\mathrm{K}_{\mathrm{j}}\right)$ else - \\
\hline
\end{tabular}

Note: the parametrisation is given in Appendix 2. t varies between 1.01 and 1.25 and $\gamma$ between 1 and 1.24. 
Figure 1: Relative country size and economic activity

Absolute output figures

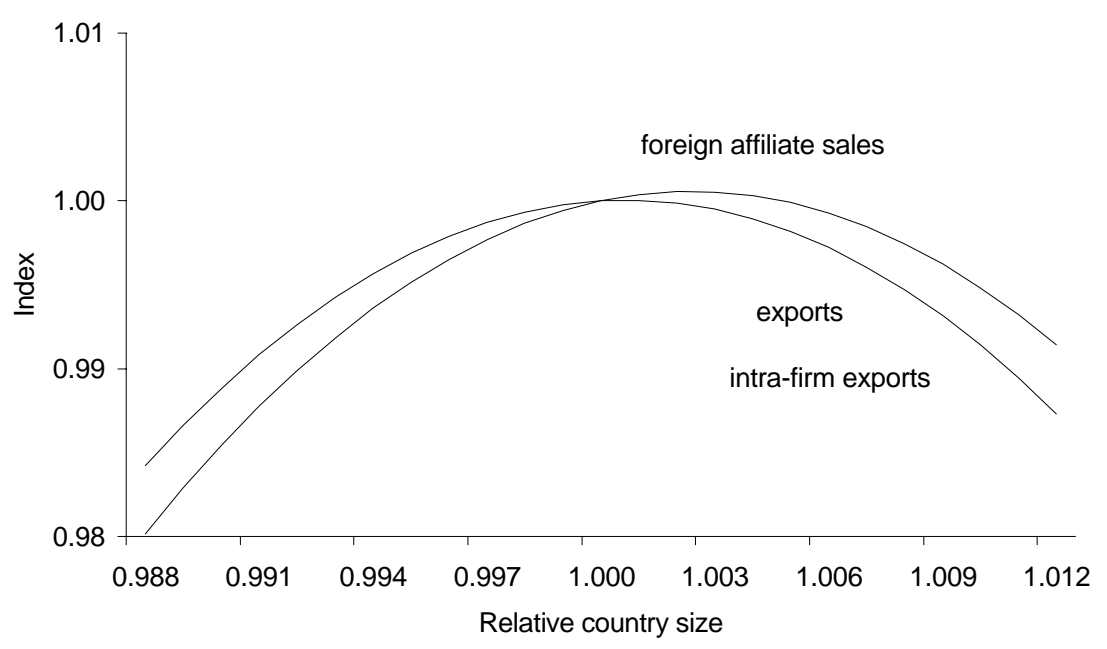

Exports, sales and FDI as percent of GNP

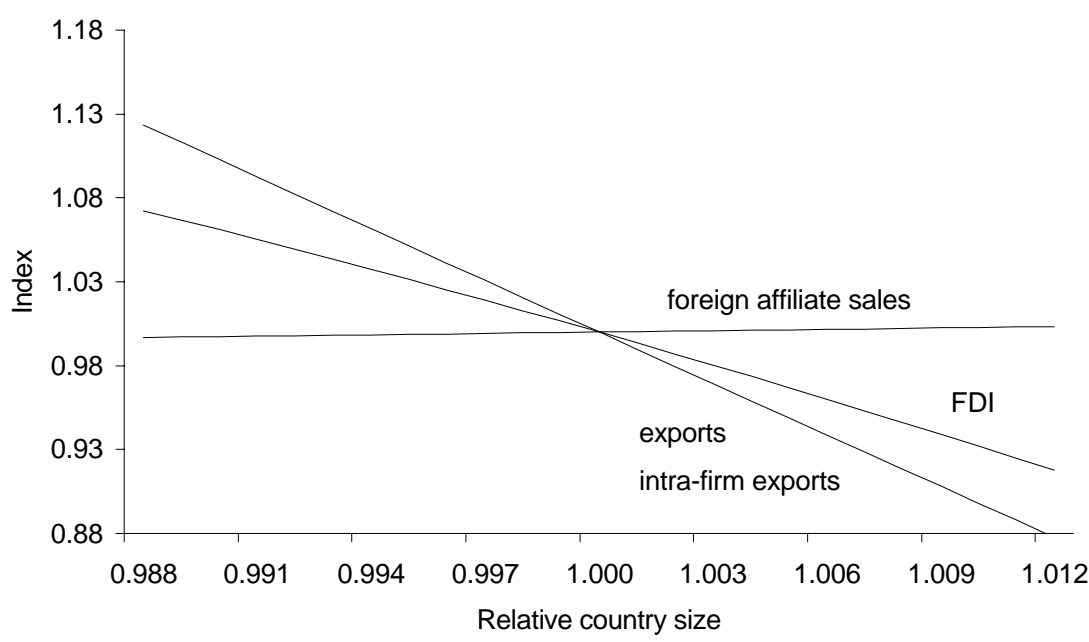

Absolute FDI figure

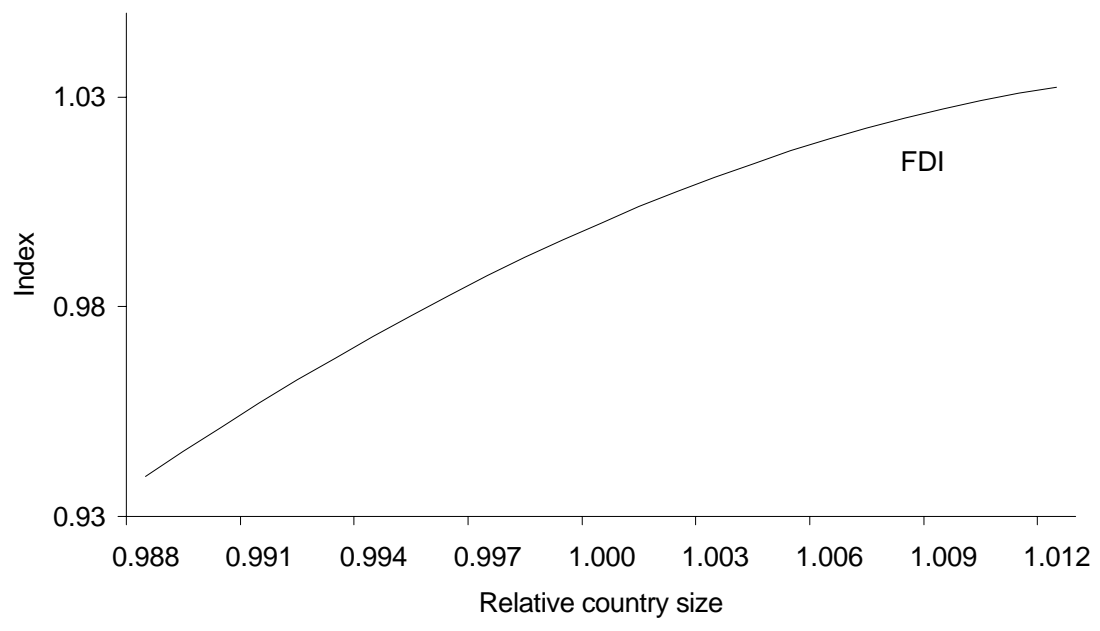

Relative wage

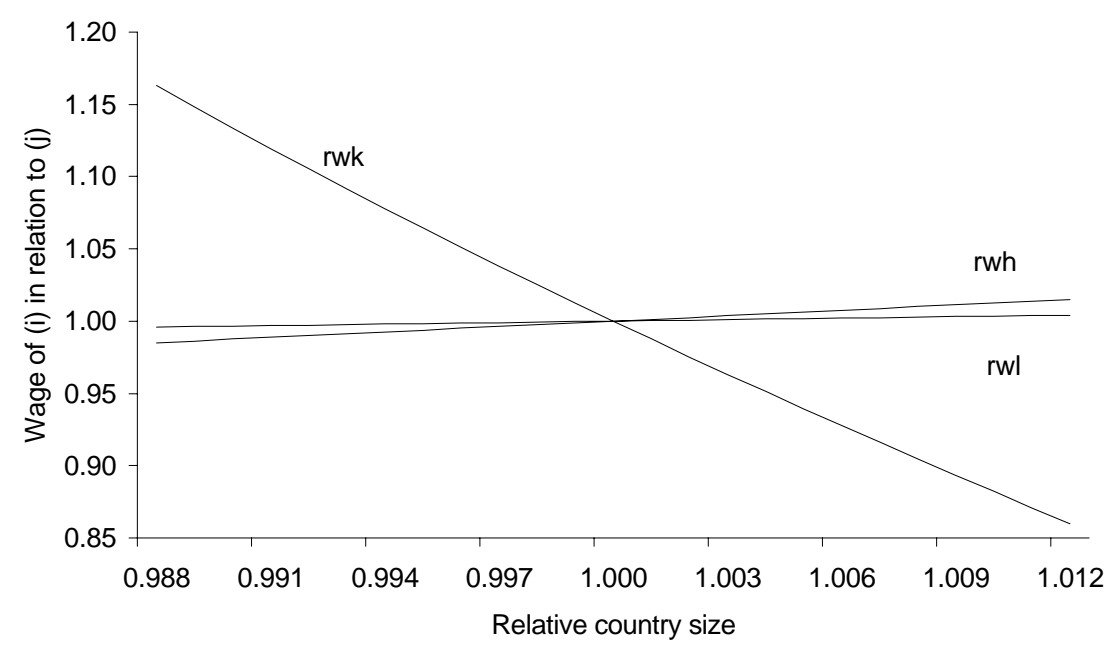

